\title{
In vitro Apatite Mineralization, Degradability, Cytocompatibility and in vivo New Bone Formation and Vascularization of Bioactive Scaffold of Polybutylene Succinate/Magnesium Phosphate/Wheat Protein Ternary Composite
}

This article was published in the following Dove Press journal: International Journal of Nanomedicine

\author{
Qinghui Zhao ${ }^{1-3, *}$ \\ Hongming Tang ${ }^{1-3, *}$ \\ Lishu Ren ${ }^{4}$ \\ Jie $\mathrm{Wei}^{4}$
}

'School of Life Sciences and Technology, Tongji University, Shanghai 200092, People's Republic of China; ${ }^{2}$ Translational Medical Center for Stem Cell Therapy \& Institute for Regenerative Medicine, Shanghai East Hospital, Tongji University School of Medicine, Shanghai 200I23. People's Republic of China; ${ }^{3}$ Shanghai Institute of Stem Cell Research and Clinical Translation, Shanghai 200I23, People's Republic of China; ${ }^{4} \mathrm{Key}$ Laboratory for Ultrafine Materials of Ministry of Education, East China University of Science and Technology, Shanghai 200237, People's Republic of China

*These authors contributed equally to this work

\begin{abstract}
Purpose: A bioactive and degradable scaffold of ternary composite with good biocompatibility and osteogenesis was developed for bone tissue repair.

Materials and Methods: Polybutylene succinate (PS:50 wt\%), magnesium phosphate (MP:40 wt\%) and wheat protein (WP:10 wt\%) composite (PMWC) scaffold was fabricated, and the biological performances of PMWC were evaluated both in vitro and vivo in this study.
\end{abstract}

Results: PMWC scaffold possessed not only interconnected macropores (400 $\mu \mathrm{m}$ to 600 $\mu \mathrm{m})$ but also micropores $(10 \mu \mathrm{m} \sim 20 \mu \mathrm{m})$ on the walls of macropores. Incorporation of MP into composite improved the apatite mineralization (bioactivity) of PMWC scaffold in simulated body fluid (SBF), and addition of WP into composite further enhanced the degradability of PMWC in PBS compared with the scaffold of PS (50 wt \%)/MP (50 wt \%) composite (PMC) and PS alone. In addition, the PMWC scaffold containing MP and WP significantly promoted the proliferation and differentiation of mouse pre-osteoblastic cell line (MC3T3-E1) cells. Moreover, the images from synchrotron radiation microcomputed tomography (SRmCT) and histological sections of the in vivo implantation suggested that the PMWC scaffold containing MP and WP prominently improved the new bone formation and ingrowth compared with PMC and PS. Furthermore, the immunohistochemical analysis further confirmed that the PMWC scaffold obviously promoted osteogenesis and vascularization in vivo compared with PMC and PS.

Conclusion: This study demonstrated that the biocompatible PMWC scaffold with improved bioactivity and degradability significantly promoted the osteogenesis and vascularization in vivo, which would have a great potential to be applied for bone tissue repair.

Keywords: polybutylene succinate, composite scaffold, cytocompatibility, osteogenesis, vascularization

\section{Introduction}

Bone tissue regeneration and reconstruction involve the use of biomedical materials to repair damaged/diseased bone tissue to restore biological functions for patients who suffer from osteoporosis, deformities, bone fractures, tumors, etc. ${ }^{1,2}$ Implantable biomedical materials with excellent biological performances and osteogenic bioactivity exhibit great potential for bone repair applications. ${ }^{3,4}$ As
Correspondence: Qinghui Zhao

Tel +86-2I-38804518

Email qinghui_zhao@I26.com
International Journal of Nanomedicine 2020:15 7279-7295 
a biomedical material for bone regeneration, bioactivity and biodegradability have crucial influences on cell responses as well as osteogenic bioactivity. ${ }^{5,6}$ Therefore, research and development of biodegradable biomedical materials with good bioactivity for bone regeneration have been paid more attention for many years.

Polybutylene succinate (PS), an aliphatic thermoplastic polyester, possesses a range of desirable properties, such as good biocompatibility, degradability, flexibility and processability. ${ }^{7}$ Notably, the degradation products of PS are demonstrated to be nontoxic and able to enter the metabolic cycles of bioorganisms. ${ }^{7-9}$ Despite these advantages, the low bioactivity, slow degradation rate, not synchronizing the new bone formation of PS as a biomaterial still does not meet the requirement of bone tissue regeneration. Consequently, improving the bioactivity and degradability are needed for the further wide application of PS for bone repair.

Studies have revealed that magnesium ion $\left(\mathrm{Mg}^{2+}\right)$ plays critical roles in bone remodeling and skeletal tissue development of the human body. ${ }^{10,11}$ Growing evidence shows that $\mathrm{Mg}^{2+}$ may improve bone mineral density and affect bone fragility, and lack of $\mathrm{Mg}^{2+}$ can, definitely, affect all stages of skeletal metabolism, leading to slower bone growth and osteoporosis. ${ }^{12,13}$ In the past few years, Mg-containing bioactive materials have received increasing attention for bone tissue repair applications. ${ }^{14,15}$ Several Mg-based biomaterials for bone repair were reported, such as Mg-associated alloys, Mg-containing bioactive glasses and their coatings, and $\mathrm{Mg}$-substituted calcium phosphate bioceramics/biocements. ${ }^{16,17}$ Unfortunately, the Mg-related inorganic scaffolds, such as magnesium phosphate (MP), even though having amazing similarity in bioactivity to commonly commercial available calcium phosphate scaffolds, generally shows a slow degradation rate, slightly unsynchronizing the formation of new bone tissue. ${ }^{18-22}$

Natural-origin polymers, such as collagen, chitosan, and implant protein, are the most important raw materials for the development of biomedical materials. ${ }^{23}$ Wheat protein (WP) as an interesting natural polymer with excellent properties including good biocompatibility, hydrophilicity, and great biodegradability has been applied in many areas, such as coating, encapsulation, and other medical applications. ${ }^{24,25}$ In a previous study, it was reported that the attachment and proliferation of osteoblasts on WP were better than poly(lactic acid) (PLA). ${ }^{26}$ In addition,
WP has been formulated with PLA and electrospun for biomedical applications. ${ }^{27}$

Substantially, natural bone tissue consists of inorganic material (apatite) and organic compounds (collagen). ${ }^{28}$ Thus, to mimic the natural bone, the biocomposites containing bioactive inorganic materials and organic polymers have been widely researched and developed, and have advantages over individual inorganic materials and polymer. ${ }^{28}$ Based on the advantages of PS, MP, and WP, in this study a novel scaffold of ternary composite (PMWC) containing $50 \mathrm{wt} \% \mathrm{PS}, 40 \mathrm{wt} \% \mathrm{MP}$ and $10 \mathrm{wt}$ $\%$ WP was prepared. The objective of this study is to develop a bioactive and degradable scaffold of ternary composite with good biological performances for bone regeneration and reconstruction. Therefore, the in vitro bioactivity, degradability, and cytocompatibility and the in vivo osteogenesis and vascularization properties of the PMWC scaffold were investigated.

\section{Materials and Methods Fabrication and Characterization of Composite Scaffolds}

MP was synthesized by using a chemical precipitation method. Briefly, magnesium nitrate (MN) and ammonium dihydrogen phosphate (ADP) were dissolved in deionized water, respectively. The MN solution was added dropwise to the ADP solution while stirring to produce white precipitates, meanwhile, $\mathrm{pH}$ value was maintained at $\sim 9$ with aqueous ammonia. After $12 \mathrm{~h}$, the precipitates were filtered, and washed with distilled water for three times, which was then cold-dried at $-50^{\circ} \mathrm{C}$ for $16 \mathrm{~h}$ to obtain MP powder. The surface morphology of MP powder was observed using scanning electron microscopy (SEM, S-4800N, Hitachi, Japan).

PS and WP were purchased from Shanghai Showa Highpolymer Co. Ltd (Shanghai, China) and Tokyo Chemical Industry Co. Ltd (Tokyo, Japan), respectively. PMWC scaffold with MP content of $50 \mathrm{wt} \%$, PS content of $40 \mathrm{wt} \%$ and WP content of $10 \mathrm{wt} \%$ were fabricated by a method of solution casting-particle leaching. Briefly, PS particles and WP powders were dissolved into dimethyl formamide (DMF). MP was added into the solution, followed by continuous stirring to disperse uniformly. Sodium chloride $(\mathrm{NaCl})$ particulates with diameters ranging from $300-500 \mu \mathrm{m}$ were used as the porogens, which were added into the slurry and stirred for $30 \mathrm{~min}$. The mixture was then cast into the molds $(\Phi 12 \times 2 \mathrm{~mm}$ and $\Phi$ 
$6 \times 6 \mathrm{~mm}$ ). The obtained samples were dried at $37^{\circ} \mathrm{C}$ for 48 $\mathrm{h}$ to remove the solvent. Afterwards, the samples were immersed into water for $48 \mathrm{~h}$ at $37^{\circ} \mathrm{C}$ to leach out the $\mathrm{NaCl}$ particulates (deionized water refreshed every $12 \mathrm{~h}$ ), and then the samples were dried at $37^{\circ} \mathrm{C}$ for $12 \mathrm{~h}$ to obtain the PMWC scaffold. The PMC containing $50 \mathrm{wt} \% \mathrm{MP}$ and $50 \mathrm{wt} \%$ PS, and PS scaffolds were prepared by the same method.

The scaffolds were characterized by X-ray diffraction (Geigerflex, Rigaku Co. Ltd, Japan) and Fourier transform infrared spectrometry (Magna-IR 550, Nicolet, East Rutherford, NJ, USA). The surface morphology and microstructure of the scaffolds were observed by scanning electron microscope (GeminiSEM 500, Gemini, Germany). The compressive strength of scaffolds was performed using a mechanical testing machine (HY-0230, Shanghai, China). Cylindrical scaffolds $(\Phi 6 \times 6 \mathrm{~mm})$ were loaded with a $1 \mathrm{kN}$ load at the speed of $1 \mathrm{~mm} / \mathrm{min}$ until crushed. The compressive strength was determined from the peak of the stress-strain curve. Five samples of each group were measured and the average value of compressive strength was obtained. The porosity of the scaffolds was determined by using Archimedes method, which was calculated as following:

$$
\text { Porosity }(\%)=\frac{(m 2-m 1)}{(m 2-m 3)} \times 100 \%
$$

Where $\mathrm{m} 1, \mathrm{~m} 2$ and $\mathrm{m} 3$ were the dry weight, wet weight and weight of the scaffolds suspended in water (subtracting buoyancy from $\mathrm{m} 1$ ), respectively.

\section{In vitro Bioactivity of Scaffolds}

In vitro bioactivity (apatite mineralization) of the scaffolds $(\Phi 12 \times 2 \mathrm{~mm})$ was evaluated by soaking the samples in $\mathrm{SBF}(\mathrm{pH}=7.4)$ for different time periods. At each time point, samples were removed and the concentrations of $\mathrm{Mg}, \mathrm{Ca}$ and $\mathrm{P}$ ions in SBF solution were determined by inductively coupled plasma atomic emission spectrometer (IRIS 1000, Thermo Elemental, Waltham, MA, USA). The samples were removed from the solution and rinsed with deionized water, and then dried in oven at $37^{\circ} \mathrm{C}$ for 24 h. The surface of the samples after soaking for 5 and 10 days was characterized by energy dispersive spectrometry (Falcon, Franklin Lake, NJ, USA) and SEM, respectively.

\section{In vitro Degradability of the Scaffolds}

The in vitro degradability of the scaffolds $(\Phi 12 \times 2 \mathrm{~mm})$ was assessed by measuring the weight loss of the samples after soaked into PBS for different time. In brief, the samples were weighed $\left(\mathrm{W}_{\mathrm{i}}\right)$ and immersed into PBS $(\mathrm{pH}=7.4)$ in sealed polyethylene bottles with a solid/liquid mass ratio of $0.1 \mathrm{~g} / 20 \mathrm{~mL}$. Each group was tested and incubated at $37^{\circ} \mathrm{C}$ in triplicate with constant shaking at $100 \mathrm{rpm}$ for 12 weeks. The PBS solution was refreshed once a week. At different time points, the samples were removed from the solution and rinsed gently with deionized water. The samples were dried at $37^{\circ} \mathrm{C}$ until the water volatilized completely, and then weighed $\left(\mathrm{W}_{\mathrm{f}}\right)$. The weight loss was calculated according to the following equation:

$$
\text { Weight }(\%)=\frac{\left(\mathrm{W}_{\mathrm{i}}-\mathrm{W}_{\mathrm{f}}\right)}{\mathrm{W}_{\mathrm{i}}} \times 100 \%
$$

The $\mathrm{pH}$ value of the PBS solution containing the scaffolds was measured using a $\mathrm{pH}$ meter (FE20K, Mettler Toledo, Switzerland) at different time points.

\section{Cell Culture on the Scaffolds}

The MC3T3-E1 cells were purchased commercially from the Cell Bank of Type Culture Collection of Chinese Academy of Sciences, Shanghai, China. The cells were cultured in DMEM (Hyclone, Thermo Fisher Scientific, Waltham, MA, USA) supplemented with 10\% FBS (Thermo Fisher Scientific, Waltham, MA, USA), 1\% penicillin $(100 \mathrm{U} / \mathrm{mL})$ and streptomycin sulphate $(100 \mu \mathrm{g} / \mathrm{mL})$ (Thermo Fisher Scientific). The cells were cultured at $37^{\circ}$ $\mathrm{C}$ in a humidified atmosphere of $5 \% \mathrm{CO}_{2}$ in air, and the culture medium was replaced every other day.

\section{Cell Morphology}

After incubation for $24 \mathrm{~h}$, the specimens were washed gently with PBS to remove the unattached cells. Then the cells on specimens were fixed with $4 \%$ paraformaldehyde for $15 \mathrm{~min}$ at room temperature and were permeabilized with $0.1 \%$ Triton X-100 in PBS for $10 \mathrm{~min}$. After washed with PBS $(\times 3)$, the cells were stained with DAPI (Sigma) and FITC (Sigma). The cell morphology was visualized using confocal laser scanning microscope (CLSM, Nikon A1R, Nikon, Japan).

\section{Cell Proliferation and Alkaline Phosphatase (ALP) Activity}

The cell proliferation was determined using the CCK-8 assay at one, three, and seven days postseeding according to a standard procedure. In brief, prior to culture with cells, the scaffold specimens $(\Phi 12 \times 2 \mathrm{~mm})$ were sonicated in ethanol for $24 \mathrm{~h}$ and sterilized under ultraviolet light for 
$24 \mathrm{~h}$. MC3T3-E1 cells with a density of $1 \times 10^{5}$ cells/well were seeded on the samples, in 24-well tissue culture plates. At each time point, the samples were taken out, gently rinsed with sterilized PBS three times, and then transferred to a new 24-well plate. A total $500 \mu \mathrm{L}$ of cell medium containing $50 \mu \mathrm{L}$ of CCK-8 solution (Dojindo Molecular Technologies Inc., Kumamoto, Japan) was added to each well and empty wells containing DMEM were set up as a negative control. After three hours, the culture medium was collected and $100 \mu \mathrm{L}$ of the supernatant was transferred into a 96-well plate and read at 450 nm using a microplate reader (Synergy HT, Bio-tek, Winooski, VT, USA) with $620 \mathrm{~nm}$ as a reference wavelength.

To evaluate the ALP activity, the samples were cultured with MC3T3-E1 cells with density of $2 \times 10^{5}$ cells/ well in 24-well culture plates at $37^{\circ} \mathrm{C}$ with $5 \% \mathrm{CO}_{2}$ in an incubator for 7, 10 and 14 days. After incubation for $24 \mathrm{~h}$, the culture medium was changed to the osteogenic induction medium, the minimum essential medium alpha modified ( $\alpha$-MEM) culture medium, which was supplemented with $10 \%$ FBS, $0.1 \mu \mathrm{M}$ dexamethasone (Sigma), $50 \mathrm{mg} / \mathrm{mL} \mathrm{L-ascorbic} \mathrm{acid} \mathrm{(Sigma),} \mathrm{and} 10 \mu \mathrm{M}$ $\beta$-glycerophosphate sodium (Sigma). These media were renewed every other day during two weeks. After 7, 10, and 14 days, the scaffolds were washed with PBS $(\times 3)$, and then lysed in a $0.2 \%$ Triton $\mathrm{X}-100$ solution through four standard freeze-thaw cycles. The cell lysates were then mixed with $50 \mu \mathrm{L}$ of p-nitrophenylphosphate (1 $\mathrm{mM}$, Sigma, USA) substrate solution $(\mathrm{pH}=9)$ composed of $0.1 \mathrm{~mol} / \mathrm{L}$ glycine and $0.5 \mathrm{mmol} / \mathrm{L} \mathrm{MgCl}_{2}$ in 1 $\mathrm{M}$ diethanolamine buffer and incubated at $37^{\circ} \mathrm{C}$ for another $15 \mathrm{~min}$. Then the reaction was terminated by adding $50 \mu \mathrm{L}$ of $\mathrm{NaOH} \quad(1 \quad \mathrm{M})$ solution. Then a spectrophotometer was used to determine the p-nitrophenolpeoduction in the reaction solution at wavelength of $405 \mathrm{~nm}$. While the bicinchoninic acid (BCA) protein assay kit measured the total protein quantity for normalization.

\section{Animal Experiments}

This study was performed according to a protocol approved by the Research Center for Laboratory Animals of Shanghai Jiao Tong University Affiliated Sixth People's Hospital, and followed with nation standard GB/T 35,892-2018 "Laboratory animal-Guideline for ethical review of animal welfare". The 24 New Zealand white rabbits (male, $\sim 2.0 \mathrm{~kg}$ ) were chosen for surgery. Systemic anesthesia was achieved with $30 \mathrm{mg} \mathrm{kg}-1$ pentobarbital sodium and local infiltration with articaine with 1:100,000 noradrenaline. A median incision was made on the left leg of the rabbit, and then a $6 \mathrm{~mm}$ radial defect was introduced in the thighbone of the rabbits. The bone defects were filled with the scaffolds with the size of $\Phi 6 \times 6 \mathrm{~mm}$. Penicillin (4000 units per body) and streptomycin (200 mg per body) were administrated subcutaneously for prevention of infection. After scaffolds were implanted for 4, 8, and 12 weeks, rabbits were sacrificed with an overdose of intravenous pentobarbital solution and bone samples were collected and placed into $4 \%$ neutral buffered formalin.

\section{3-D SRmCT Imaging}

In order to evaluate the process of bone defects repair after the implantation, synchrotron radiation micro computed tomography (SRmCT) measurements were performed at beam line BL13W of Shanghai Synchrotron Radiation Facility (SSRF, Shanghai, China) using a monochromatic beam with an energy of $30 \mathrm{keV}$ and a sample-to-detector distance of $1.5 \mathrm{~m}$. In the current study, a $4000 \times 2500 \mathrm{CCD}$ detector with the pixel size set to $6 \mu \mathrm{m}$ was used to record images. 1500 projections within an angular range of $180^{\circ}$ were taken and the exposure time amounted to four seconds per projection. 2-D images were taken within a view of $6 \mathrm{~mm}$ in height and the samples were scanned from the top to the bottom successively. Finally, the 2-D images of the whole sample were integrated by Adobe Photoshop CS5 Software (Adobe Systems Incorporated, San Jose, CA, USA). 3-D images of the samples were reconstructed using a filtered backprojection algorithm. The images were finally converted to an eight-bit data format, proportional to the measured attenuation coefficients of the voxels. The VG Studio MAX 2.0 software (Volume Graphics, Heidelberg, Germany) served for the visualization of the tomographic data.

\section{Histological Evaluation}

After SRmCT scanning, the bone samples were decalcified in $10 \%$ EDTA $(\mathrm{pH}=7.0)$ for around 30 days at room temperature, and then washed with double-distilled water gently, dehydrated in ascending grades of alcohol, and embedded in paraffin. Serial section of the samples was made into $20 \mu \mathrm{m}$ (thickness) by a microtome and then frozen at $-20^{\circ} \mathrm{C}$. One section was selected out of $10 \mathrm{sec}-$ tions of each sample were performed with H\&E staining. The new bone formation within scaffolds was observed under a light microscope (TE2000U, Nikon, Japan). 
The histological sections were used to quantitatively determine the amount of newly formed bone after the samples implanted in vivo for different times. Three pieces of histological sections were randomly selected from the PS, PMC, and PMWC. After H\&E staining, each section was observed under light microscope, and at least six images were randomly obtained from the same section. Using image analytical software ImageProPlus (Media Cybernetics, Rockville, MD, USA), new bone area was expressed as percentage of newly formed bone area within the original bone defect area, after the scaffolds implanted for 4,8 , and 12 weeks.

\section{Immunohistochemical Analysis}

Decalcified histological sections were mounted on amino-propyl-triethoxy-silane coated slides. These sections were then dewaxed in descending concentrations of alcohol and rehydrated. The slides were immersed into $3 \%$ hydrogen peroxide to block endogenous peroxidases and rinsed with PBS. Then the slides were immersed into $0.1 \%$ Triton X100 in PBS for 20 min to allow penetration of the membrane. Antigen retrieval was carried out in a $10 \mathrm{mM}$ warm citrate buffer at $60^{\circ}$ $\mathrm{C}$ for $15 \mathrm{~min}$ at $\mathrm{pH}=6.0$. Afterwards, the slides were rinsed gently with PBS. Specific sites were saturated with normal goat serum for $40 \mathrm{~min}$ at $37^{\circ} \mathrm{C}$. The sections were incubated with the specific antisera (all diluted 1:100) overnight at $4^{\circ} \mathrm{C}$.

The histological sections were deparaffinized and incubated with primary antibodies against BMP-2 (1:25 dilution; Abcam, Inc., Cambridge, UK) to identify osteogenesis before applying fluorescent donkey polyclonal secondary antibody IgG (diluted 1:200, Invitrogen) for $30 \mathrm{~min}$ at room temperature. Thereafter, the sections were incubated for 30 min with DAPI for counterstain. The slides were then examined microscopically (TE2000U, Nikon, Japan).

Alternatively, deparaffinized sections were incubated with primary antibodies against VEGF (1:100 dilution, Abcam) to identify blood vessels, following incubation with a secondary antibody. Then DAB substrate (DAKO, Cambridge, UK) was used to stain the slides, and the slides were counterstained with hematoxylin and mounted. At last, slides were assessed by using a light microscope. Quantitatively analysis of the positive expressions of BMP-2 and VEGF was performed by using Image-ProPlus after the implantation of scaffolds at 4,8 , and 12 weeks.

\section{Statistical Analysis}

All quantitative data expressed as the mean \pm SD were analyzed with Origin 8.0 (Origin Lab Corporation, USA). Statistical comparisons were carried out using analyses of one-way ANOVA followed by Tukey's post hoc test. Statistical significance was attained with greater than 95\% CI $(p<0.05)$.

\section{Results \\ Characterizations of the Composite Scaffolds}

Figure 1A and B shows the scanning electron microscopy (SEM) images of MP powders at different magnifications. Clearly, the MP particles displayed flake-like shapes with an irregular size of $\sim 500 \mathrm{~nm}$ Figure 1C-H shows the SEM images of the PS, PMC and PMWC scaffolds. Macroscopically, all scaffolds showed well interconnected macropores with a pore size ranging from $400 \mu \mathrm{m}$ to $600 \mu \mathrm{m}$. The PS images at higher magnification (Figure 1D) showed a smooth surface. Conversely, PMC exhibited a slightly coarse surface because of the introduction of MP particles into PS. More interestingly, the PMWC not only possessed macropores, but also had micropores ranging from $10 \mu \mathrm{m}$ to $20 \mu \mathrm{m}$ on the walls of the macropores (Figure $1 \mathrm{H}$ ).

The compositions of PS, PMC, PMWC, MP, and WP were confirmed by X-ray diffraction (XRD) as shown in Figure 2A. The peaks at $2 \theta=19.3^{\circ}, 22.2^{\circ}$, attributed to PS, suggested that PS had good crystallization, whereas the peaks at $2 \theta=12.2^{\circ}, 13.5^{\circ}, 21.1^{\circ}, 23.2^{\circ}, 29.6^{\circ}, 31.4^{\circ}, 34.7^{\circ}$ and $36.4^{\circ}$, assigned to MP, demonstrated the weak crystallization of MP. The broad, instead of sharp, peak at around $2 \theta=20^{\circ}$ in the XRD of WP indicated amorphous phase.

Figure 2B illustrates the Fourier transform infrared (FTIR) spectra of PS, PMC and PMWC, MP and WP. The characteristic band of PS at $1250-1000 \mathrm{~cm}^{-1}$ corresponded to the $\mathrm{C}=\mathrm{O}$ stretching of the ester carbonyl group. The characteristic bands at $1746,1308,1197$ and $1042 \mathrm{~cm}^{-1}$ of MP were assigned to the $\mathrm{P}-\mathrm{O}$ stretching and bending. The characteristic band of WP at $1700-1600 \mathrm{~cm}^{-1}$ corresponded to the $\mathrm{CO}-\mathrm{NH}-$ stretching and bending. Evidently, the spectra of the PMC and PMWC exhibited the characteristic bands from PS and MP, and from PS, MP, and WP, respectively.

The results revealed that the compressive strengths of PS, PMC and PMWC scaffolds were 1.9 MPa, 2.8 MPa and 3.0 MPa, respectively. Moreover, the porosity of PS, PMC and PMWC scaffolds were $71.3 \%, 73.2 \%$ and $72.1 \%$, respectively. 

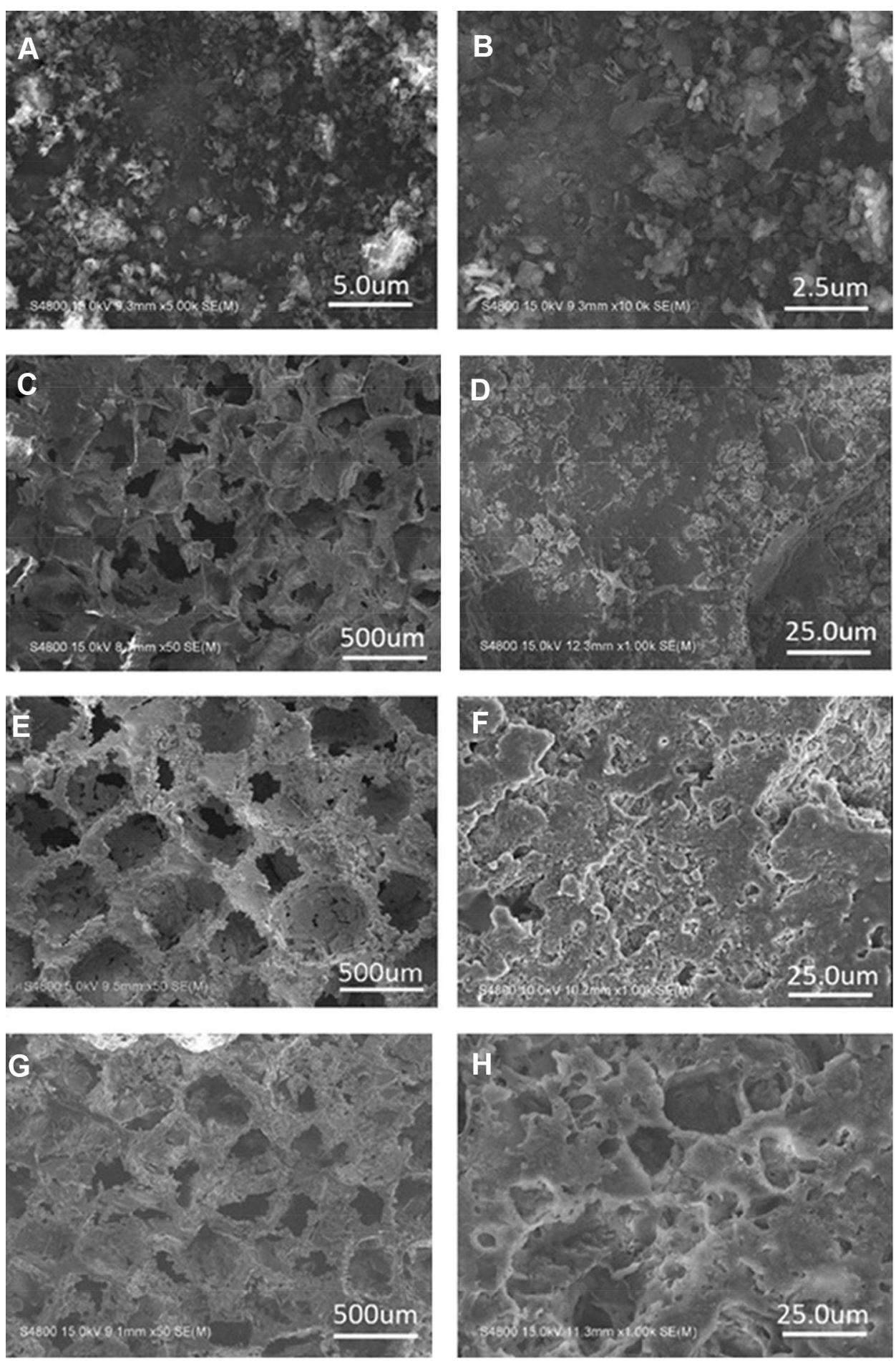

Figure I SEM images of MP powders (A, B), PS (C, D), PMC (E, F), and PMWC (G, H) at different magnifications.

Abbreviations: SEM, scanning electron microscope; MP, magnesium phosphate; PS, polybutylene succinate; PMC, polybutylene succinate-magnesium phosphate composite scaffolds; PMWC, polybutylene succinate-magnesium phosphate-wheat protein composite scaffolds.

\section{In vitro Bioactivity}

The in vitro bioactivity (apatite mineralization) of scaffolds was investigated by soaking the samples in simulated body fluid (SBF) for different time as shown in Figure 3.
SEM images of the scaffolds after immersed into SBF for 5 (Figure 3A, C, E) and 10 (Figure 3B, D, F) days were presented. PS, PMC and PMWC scaffolds showed different morphologies. Evidently, PS surface did not show 

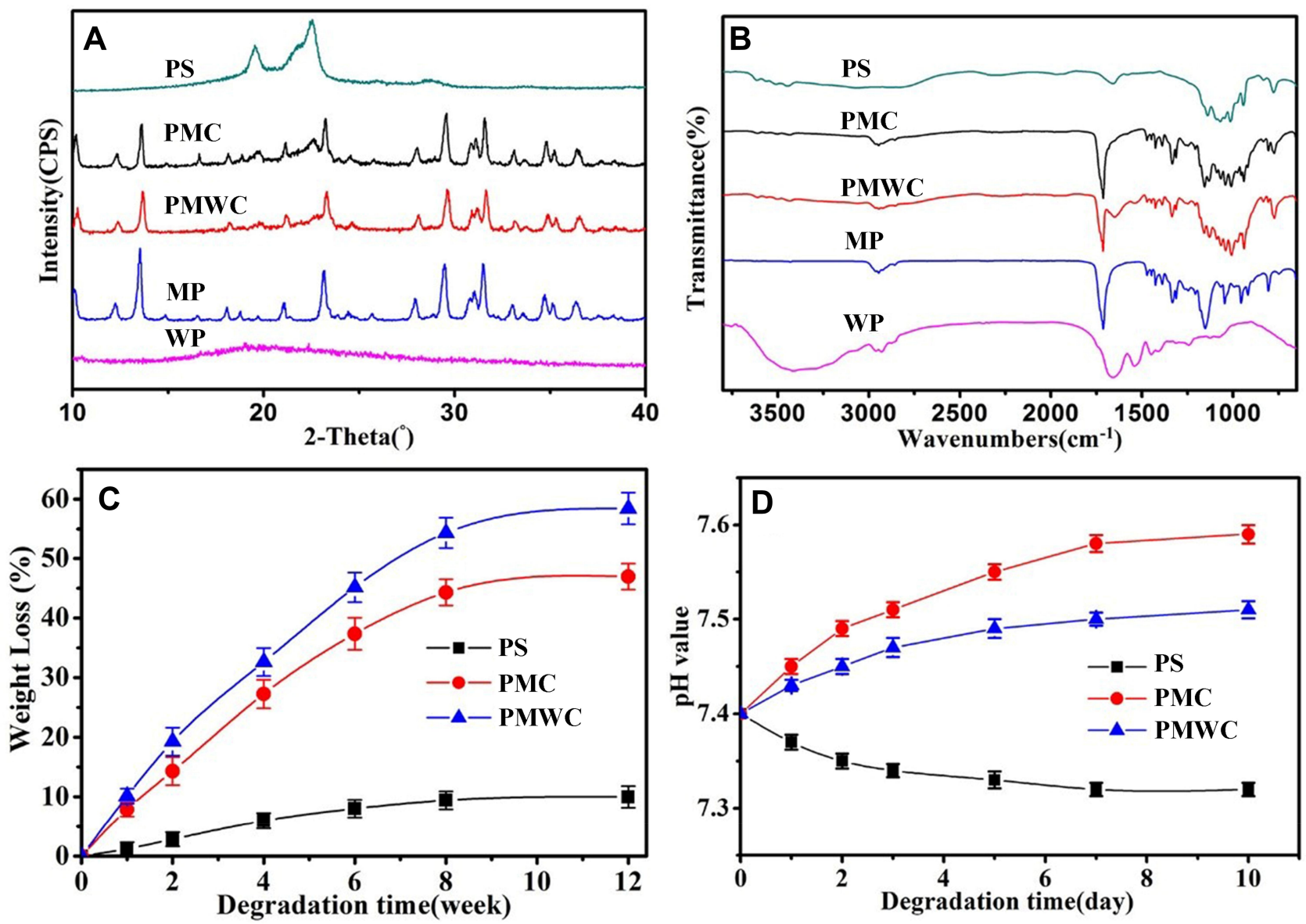

Figure 2 XRD (A) and FTIR (B) of PS, PMC, PMWC, MP and WP, and weight loss (C) and pH change (D) after PS, PMC and PMWC immersed into PBS for different time. Abbreviations: $X R D, X$-ray diffraction; FTIR, Fourier transform infrared spectrometry; MP, magnesium phosphate; PS, polybutylene succinate; PMC, polybutylene succinate-magnesium phosphate composite scaffolds; PMWC, polybutylene succinate-magnesium phosphate-wheat protein composite scaffolds; WP, wheat protein; PBS, phosphate buffered saline.

change (no apatite formation on scaffold surface) before and after immersion in SBF, indicating poor bioactivity of PS. In contrast, a layer of ball-like particles, the characteristic of apatite, formed in all composite scaffolds with the incorporation of MP after immersion in SBF. Clearly, the PMWC were fully covered with a new layer of apatite after 10 days, with bigger particle size and more uniform coverage than PMC, an evidence of faster apatite growth, meaning better bioactivity, on PMWC.

Figure $3 \mathrm{G}$ and $\mathrm{H}$ presented the energy-dispersive spectroscopy (EDS) of PMC and PMWC scaffolds after soaking into SBF for different times, respectively. At 5 or 10 days, $\mathrm{P}$ and $\mathrm{Ca}$ peaks appeared and increased visibly, indicating Ca-P-containing particles deposited on the scaffolds. This should be attributed to the precipitation of apatite layer on scaffolds. Compared with PMC, PMWC showed higher peak intensity, consistently, evidencing the better bioactivity of PMWC than PMC. These results demonstrated that apatite formation was induced on PMC, due to the addition of MP, and the WP in PMWC further promoted the apatite mineralization compared with PMC.

\section{lonic Concentration Changes of SBF Solution}

Changes in the ion concentrations of SBF solution were investigated using inductively coupled plasma-atomic emission spectroscopy (ICP-AES) after the immersion of PMC and PMWC scaffolds for different time periods as shown in Figure 4. Both $\mathrm{Mg}$ and $\mathrm{P}$ ion concentrations in SBF rose with time, but at different rates, while $\mathrm{Ca}$ ion concentration in $\mathrm{SBF}$ declined with time. For $\mathrm{PMC}$, at 10 days, the $\mathrm{Mg}, \mathrm{P}$, and $\mathrm{Ca}$ ions concentrations reached $75.3 \mathrm{mgL}^{-1}, 52.6 \mathrm{mg} \mathrm{L}^{-1}$, and $53.6 \mathrm{mg} \mathrm{L}^{-1}$, respectively. Differently, the concentration of $\mathrm{Mg}, \mathrm{P}$ and $\mathrm{Ca}$ ions in SBF solution soaking PMWC reached $92.0 \mathrm{mgL}^{-1}, 65.0 \mathrm{mgL}^{-1}$, and $49.6 \mathrm{mgL}^{-1}$ at 10 days, 

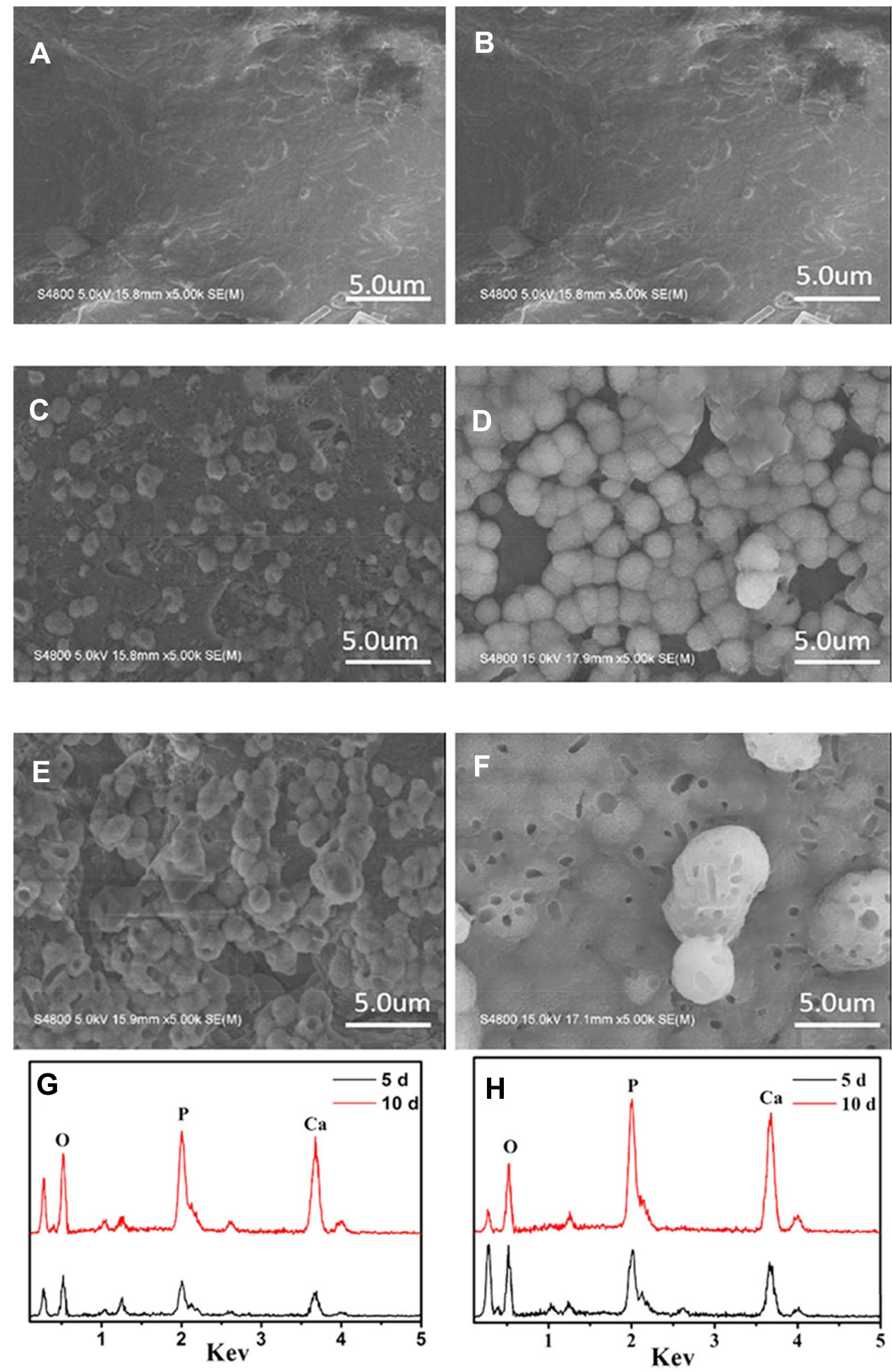

Figure 3 SEM images of surface morphology of PS (A, B), PMC (C, D), and PMWC (E, F) immersed into SBF for $5(\mathbf{A}, \mathbf{C}, \mathbf{E})$ and 10 (B, D, F) days. EDS of PMC (G) and PMWC (H) immersed in SBF for 5 and 10 days, respectively.

Abbreviations: SEM, scanning electron microscope; PS, polybutylene succinate; PMC, polybutylene succinate-magnesium phosphate composite scaffolds; PMW, polybutylene succinate-magnesium phosphate-wheat protein composite scaffolds; SBF, simulated body fluid.

respectively. When the samples were immersed in SBF, Mg and $\mathrm{P}$ ions released from scaffolds into SBF solution, while $\mathrm{Ca}$ and $\mathrm{P}$ ions in the solution deposited to form apatite on the material surfaces, and the release of $\mathrm{P}$ was the leading process, in agreement with the EDS analysis in Figure 3G and $\mathrm{H}$. 

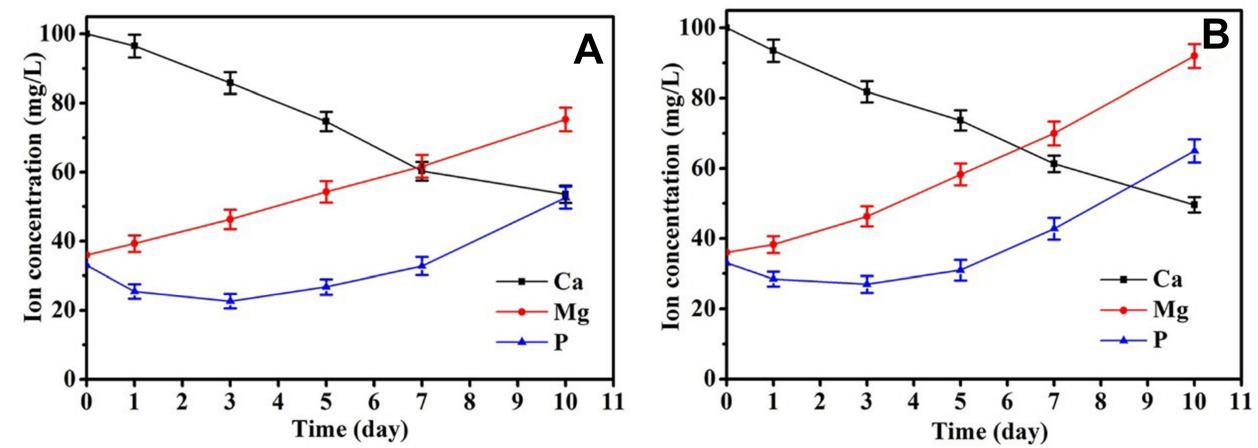

Figure 4 Changes of ion concentrations in solution after PMC (A) and PMWC (B) immersed into SBF for different time. Abbreviations: PMC, polybutylene succinate-magnesium phosphate composite scaffolds; PMWC, polybutylene succinate-magnesium phosphate-wheat protein composite scaffolds; SBF, simulated body fluid.

\section{In vitro Degradability and $\mathrm{pH}$ Change in $\mathrm{PBS}$}

As a great candidate scaffold for bone tissue repair, the degradation kinetic was expected to synchronize the newly formed bone tissue. Hence, the evaluation of degradation of biomaterials was of importance prior to further clinical application. Figure $2 \mathrm{C}$ shows the weight loss of the scaffolds after immersion into PBS for different time intervals. Encouragingly, the weight loss of PMWC scaffolds increased with the time and reached $58.43 \mathrm{w} \%$ at 12 weeks, while PMC and PS were $46.95 \mathrm{wt} \%$ and $9.98 \mathrm{wt}$ $\%$, respectively. The results indicated that the incorporation of WP into PMWC improved the degradation kinetics, inducing a faster degradation rate than PMC.

The $\mathrm{pH}$ change in solution with time after the samples soaked into PBS for different time as shown in Figure 2D. It was found that the $\mathrm{pH}$ value corresponding to PMWC increased from initial 7.40 to 7.51 at 10 days and corresponding to PMC increased from initial 7.40 to 7.59 , whereas the $\mathrm{pH}$ for PS reduced from initial 7.40 to 7.32 . Significantly, the addition of MP into PS efficiently increased the alkaline condition, which deviated from the normal physical $\mathrm{pH}$ of 7.4 too much. Interestingly, the addition of WP into the PMC not only buffered the increase of $\mathrm{pH}$ value during degradation, slightly higher than physical $\mathrm{pH}$, but also inhibited the occurrence of acidity, as observed in PS degradation.

\section{Cell Morphology, Proliferation and Differentiation}

Figure 5 illustrates the confocal laser scanning microscopy (CLSM) images of the MC3T3-E1 cell growth on the scaffolds stained by fluorescein isothiocyanate (FITC) and DAPI, at 1, 3 and 7 days. The cells exhibited a typical fibroblastic morphology with more cytoplasmic extensions and better filopodial attachments on PMC than PS, and PMWC scaffolds showed even better cell spreading than PMC. Alternatively, the cells showed denser growth on composite scaffolds, especially, PMWC, as compared with PS.

Figure 6A showed the proliferation of MC3T3-E1 cells on scaffolds measured by the cell counting kit- 8 (CCK-8) assay. The relative proliferation rates for these scaffolds in tissue culture plate (TCP) increased with culture time, meaning that the cell numbers on scaffolds were sustainably increased. Notably, the cells on PMWC exhibited a prominently higher proliferation rate than both PMC and PS at seven days. However, at three and seven days, no statistical difference was found among PS, PMC and PMWC scaffolds at one and three days. Figure 6B shows the alkaline phosphatase (ALP) activity of MC3T3-E1 cells on scaffolds at 7, 10, and 14 days. The MC3T3-E1 cells on PS showed lower ALP activity than those cultured on PMWC and PMC at all the time points.

\section{Macro Observation and SRmCT Analysis}

The photos of the bone defects implanted with PS, PMC, and PMWC scaffolds for 4, 8, and 12 weeks were shown in Figure 7. Visibly, the bone defects were gradually healed with time. After 12 weeks, more significantly, the bone defects implanted with PMWC were replaced with newly formed bone tissue, whereas they were not completely renovated for PS.

The bone samples after implantation in vivo for 4,8 , and 12 weeks were scanned in SRmCT system to evaluate the in vivo osteogenesis of the scaffold (Figure 8). At four weeks, the 3-D images from SRmCT revealed that obvious new bone formation in PMWC scaffolds 


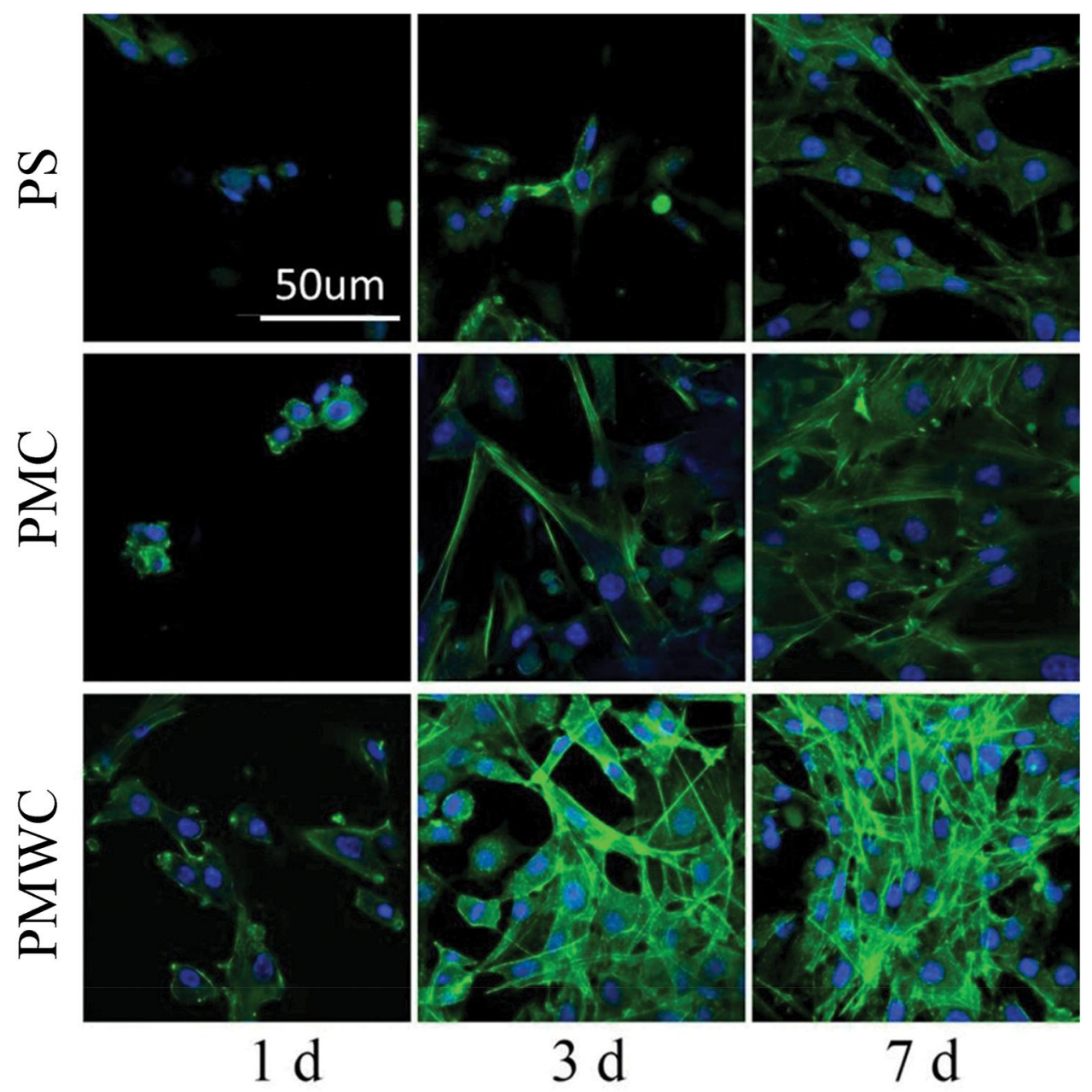

Figure 5 CLSM images of MC3T3-EI cells stained by FITC (green) and DAPI (blue) after cultured on PS, PMC, and PMWC for I, 3 , and 7 days. Scale bar of 50 mm is applicable to all.

Abbreviations: CLSM, confocal laser scanning microscopy; MC3T3-EI, mouse pre-osteoblastic cell line; FITC, fluorescein isothiocyanate; PS, polybutylene succinate; PMC, polybutylene succinate-magnesium phosphate composite scaffolds; PMWC, polybutylene succinate-magnesium phosphate-wheat protein composite scaffolds.

occurred throughout the cross section of the defects. Conversely, smaller amount of new bone in PMC was recognized at the native bone margins and the defect periphery. In addition, the PS exhibited bone formation at the outer surface of the cylinder, however, inferior compared with PMC, especially PMWC. This difference among PS, PMC, and PMWC was also found at eight weeks, and the bone repair was slightly improved compared with four weeks. At 12 weeks, the most extensive bone ingrowth, along with the formation of new bone cortex, was observed throughout PMWC. The new bone area for PMC increased with time and was lower than PMWC. This situation was even worse for PS, which showed significantly less bone accumulation with a large area of hole visible in the defect sites, and the bone defects, therefore, remained unrepaired.

\section{Histological Evaluation}

Figure 9A shows the images of histological sections, visualized by H\&E staining, after PS, PMC, and PMWC scaffolds implanted into the femoral defects of rabbits for different time. After four weeks postimplantation, a few new bone tissues were found in PMC and PMWC and increased gradually with implantation time. At 12 weeks, a large amount of new bone tissues were observed in the PMWC. New bone tissues were also found in PMC, but the area was smaller than that in PMWC. On the contrary, the new bone tissues in PS were less than PMC and PMWC from 4 to 12 weeks postimplantation.

Figure 9B shows the quantitative analysis of the new bone area in PS, PMC, and PMWC scaffolds at different time points. Consistently, the new bone area increased with the implantation time for all scaffolds, but the bone 

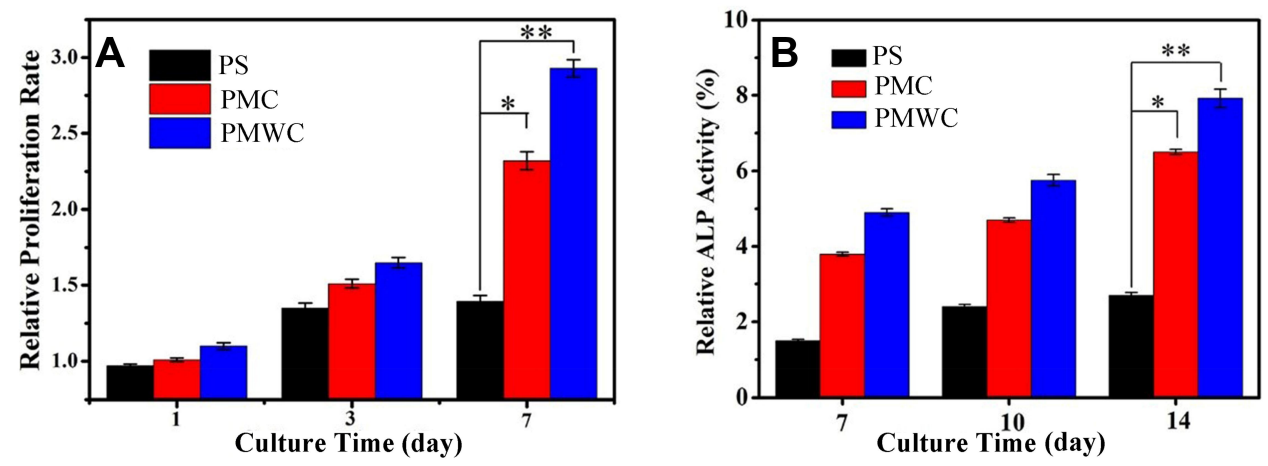

Figure 6 Proliferation (A) and ALP activity (B) of MC3TS-EI cells cultured on PS, PMC, and PMWC at different time points. $* p<0.05$ and $* * p<0.01$ relative to PS. Abbreviations: ALP, alkaline phosphatase; MC3T3-EI, mouse pre-osteoblastic cell line; PS, polybutylene succinate; PMC, polybutylene succinate-magnesium phosphate composite scaffolds; PMWC, polybutylene succinate-magnesium phosphate-wheat protein composite scaffolds.
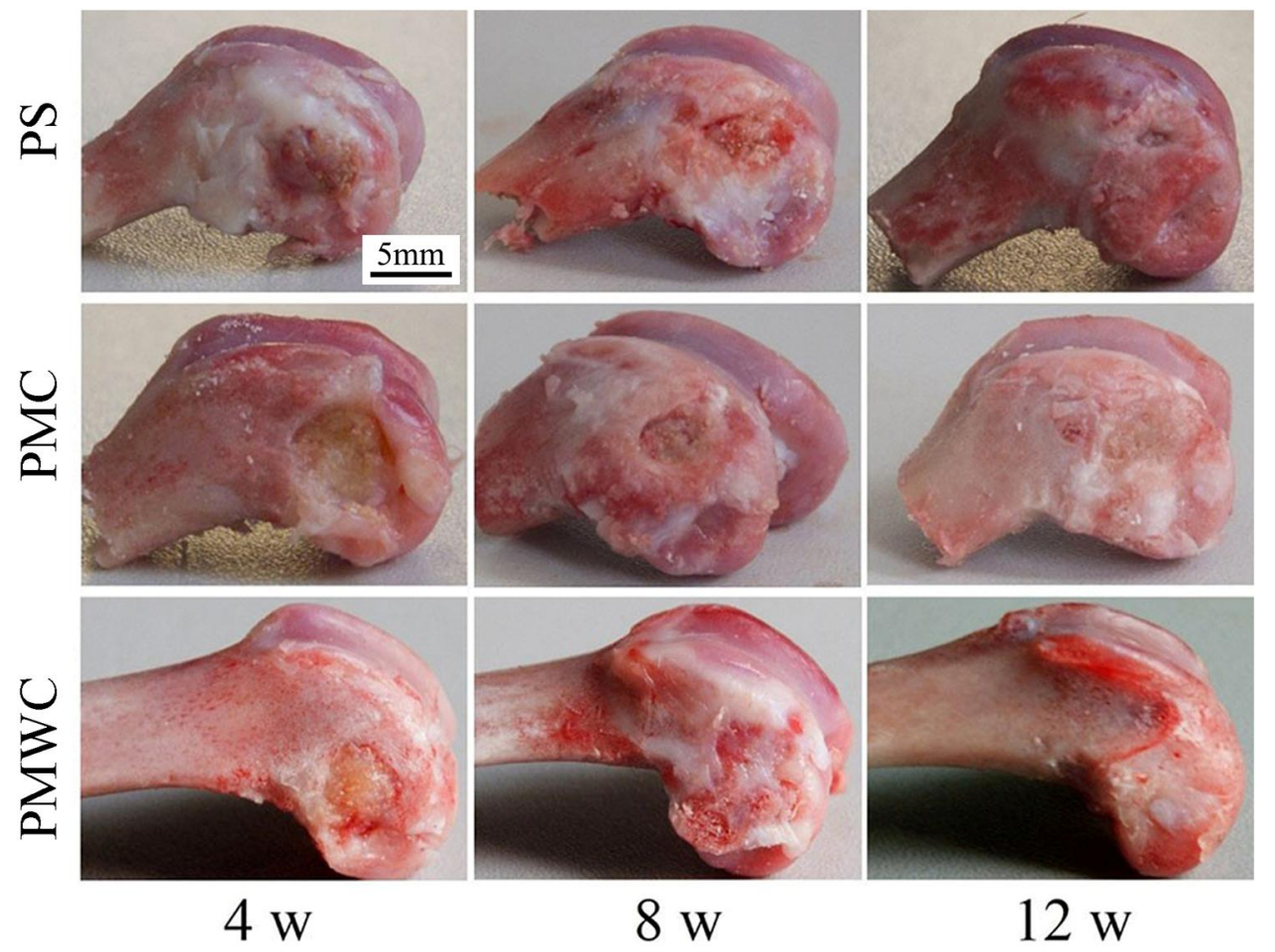

Figure 7 Digital photographs of PS, PMC, and PMWC implanted into the femoral defects of rabbits for 4, 8, and I2 weeks.

Abbreviations: PS, polybutylene succinate; PMC, polybutylene succinate-magnesium phosphate composite scaffolds; PMWC, polybutylene succinate-magnesium phosphate-wheat protein composite scaffolds.

regeneration in PS was extremely sluggish from 4 to 12 weeks, relative to other groups. At four weeks, there was no significant difference between the PMC and PMWC. However, at 8 and 12 weeks, the new bone areas for PMWC ( $8 \mathrm{w}: 55.46 \%, 12 \mathrm{w}: 90.87 \%$ ) were prominently higher than PMC (8 w:43.77\%, $12 \mathrm{w}: 75.35 \%)$ and PS (8 $\mathrm{w}: 8.12 \%$ and $12 \mathrm{w}: 10.27 \%)$.

\section{Immunohistochemical Analysis}

Figure 10 shows the immunohistochemical staining of bone morphogenetic protein-2 (BMP-2, Figure 10A) and vascular endothelial growth factor (VEGF, Figure 10C) for PS, PMC, and PMWC scaffolds after implanted in vivo for 4,8 , and 12 weeks. Overall, the BMP-2 staining area (brown) increased with implantation time, indicating that 


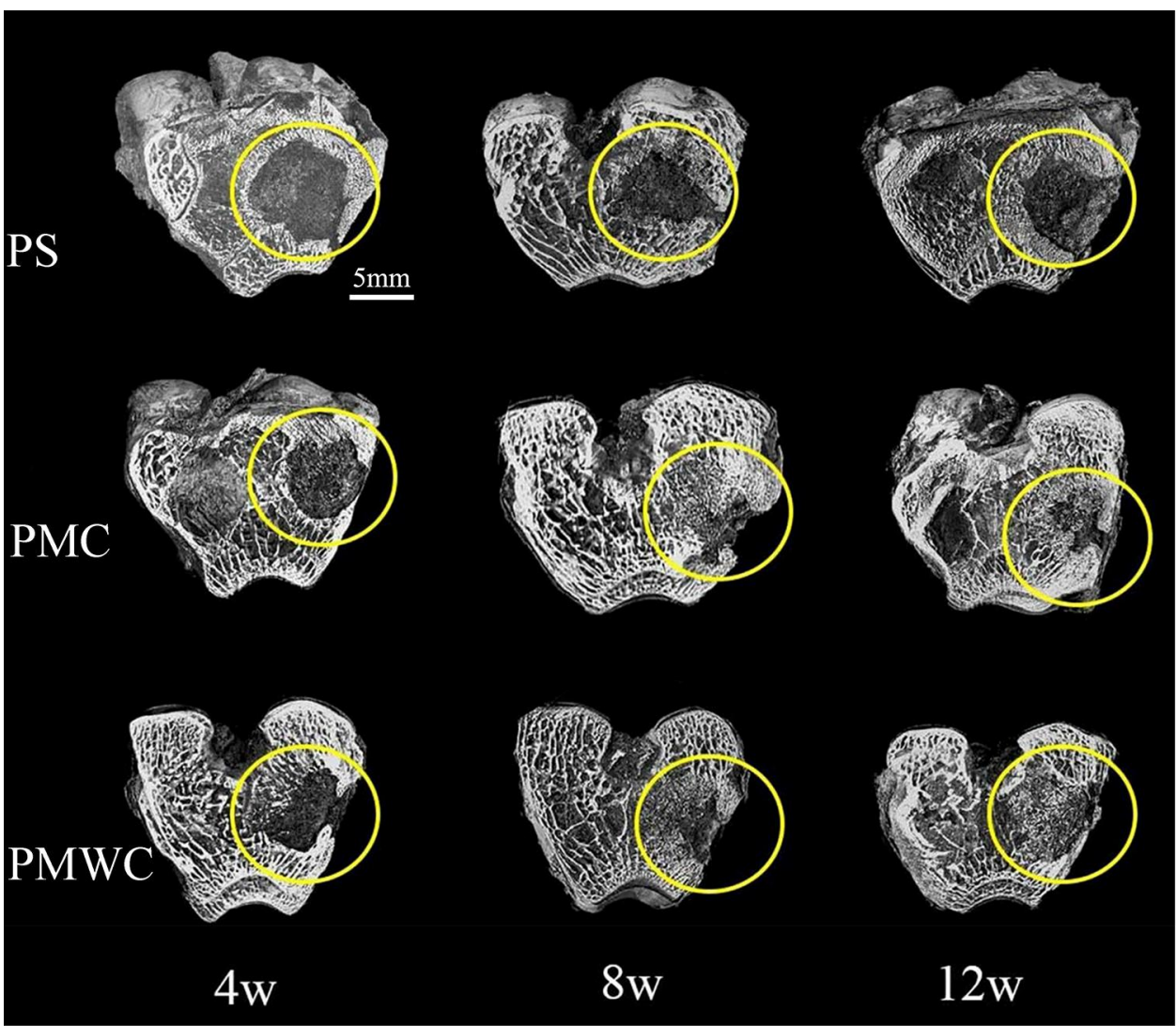

Figure 8 3-D reconstruction images of bone samples from SRmCT after PS, PMC, and PMWC implanted into bone defects of rabbit femur for 4, 8, and I2 weeks. Abbreviations: SRmCT, synchrotron radiation micro-computed tomography; PS, polybutylene succinate; PMC, polybutylene succinate-magnesium phosphate composite scaffolds; PMWC, polybutylene succinate-magnesium phosphate-wheat protein composite scaffolds.
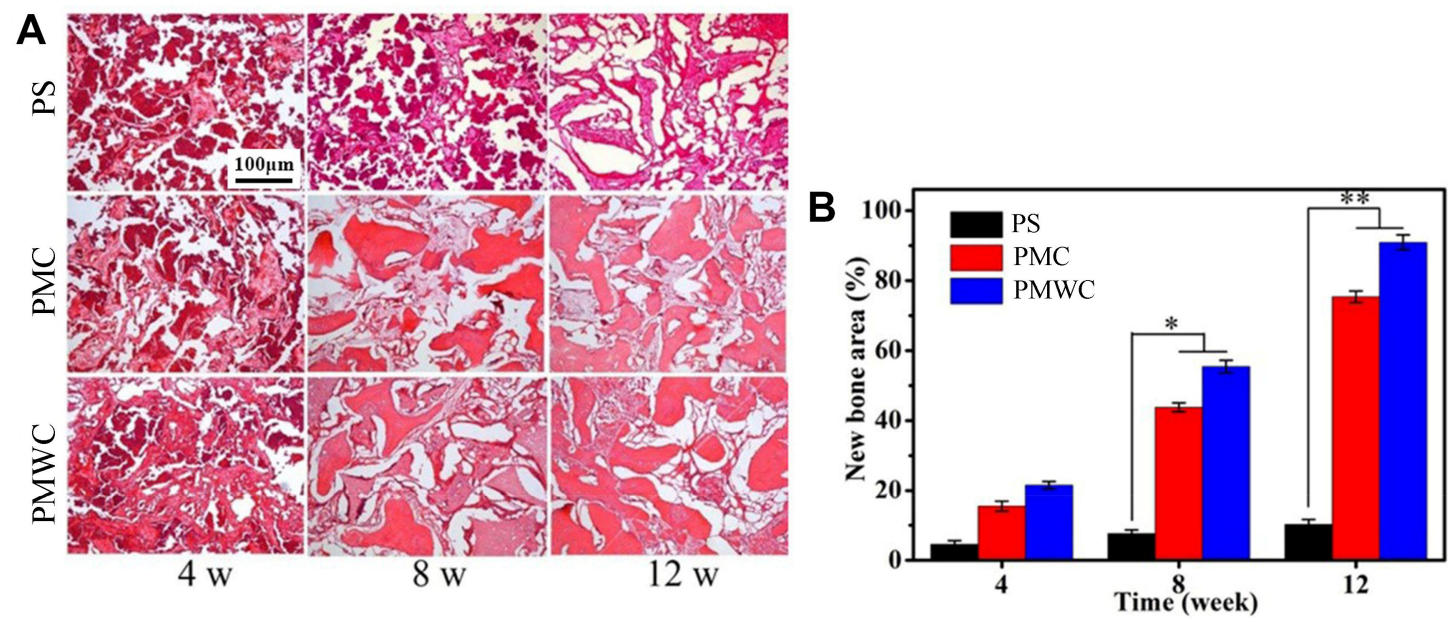

Figure 9 (A) Histological evaluation (H\&E staining) of new bone formation and materials degradation after PS, PMC, and PMWC implanted in vivo for 4, 8, and I2 weeks. (B) Quantitative analysis of the new bone area by histological sections after PS, PMC, and PMWC implanted in vivo for 4, 8 and 12 weeks. ${ }^{p}<<0.05$ and **p $<<0.01$ relative to Ps. Abbreviations: PS, polybutylene succinate; PMC, polybutylene succinate-magnesium phosphate composite scaffolds; PMWC, polybutylene succinate-magnesium phosphate-wheat protein composite scaffolds. 

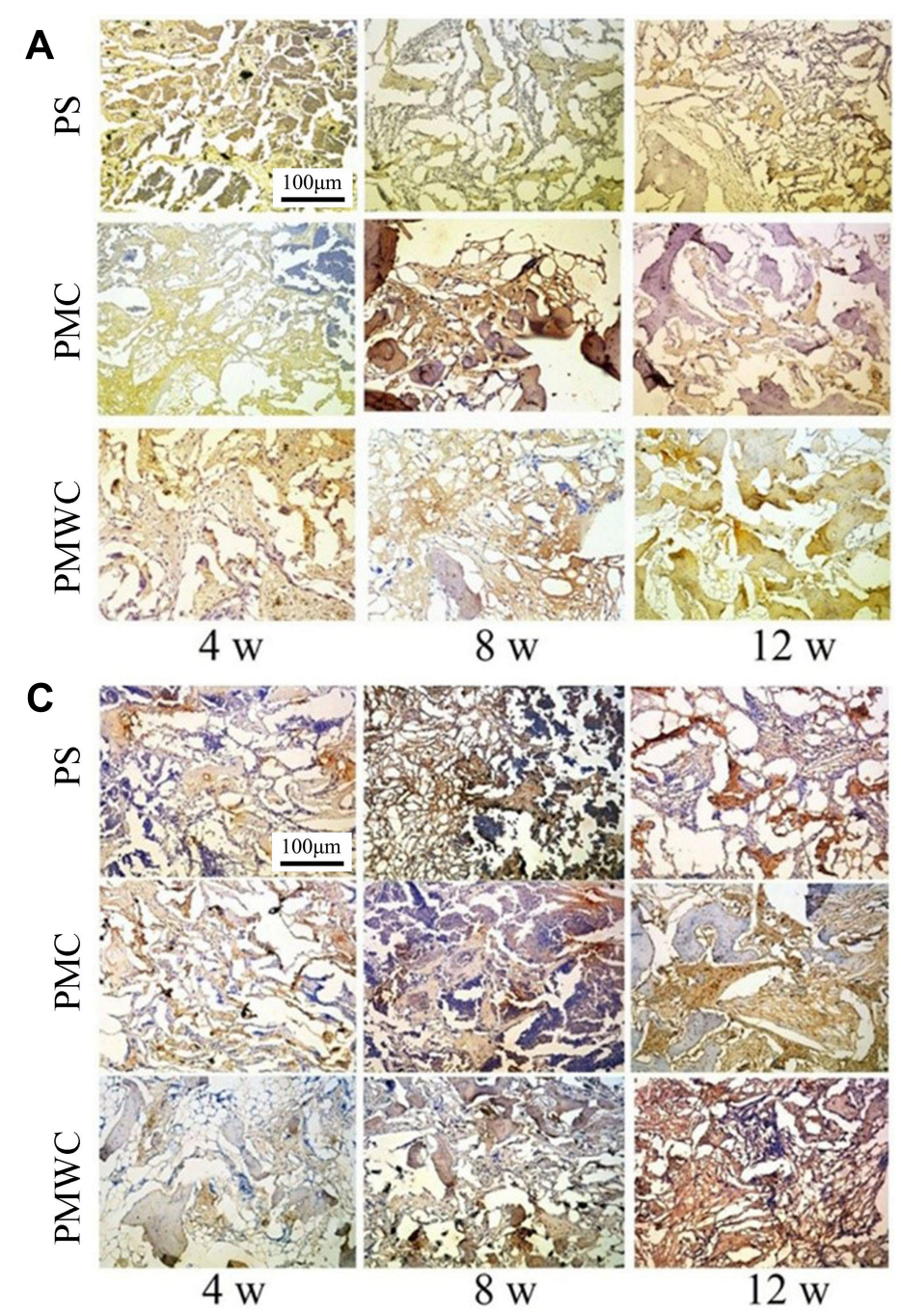
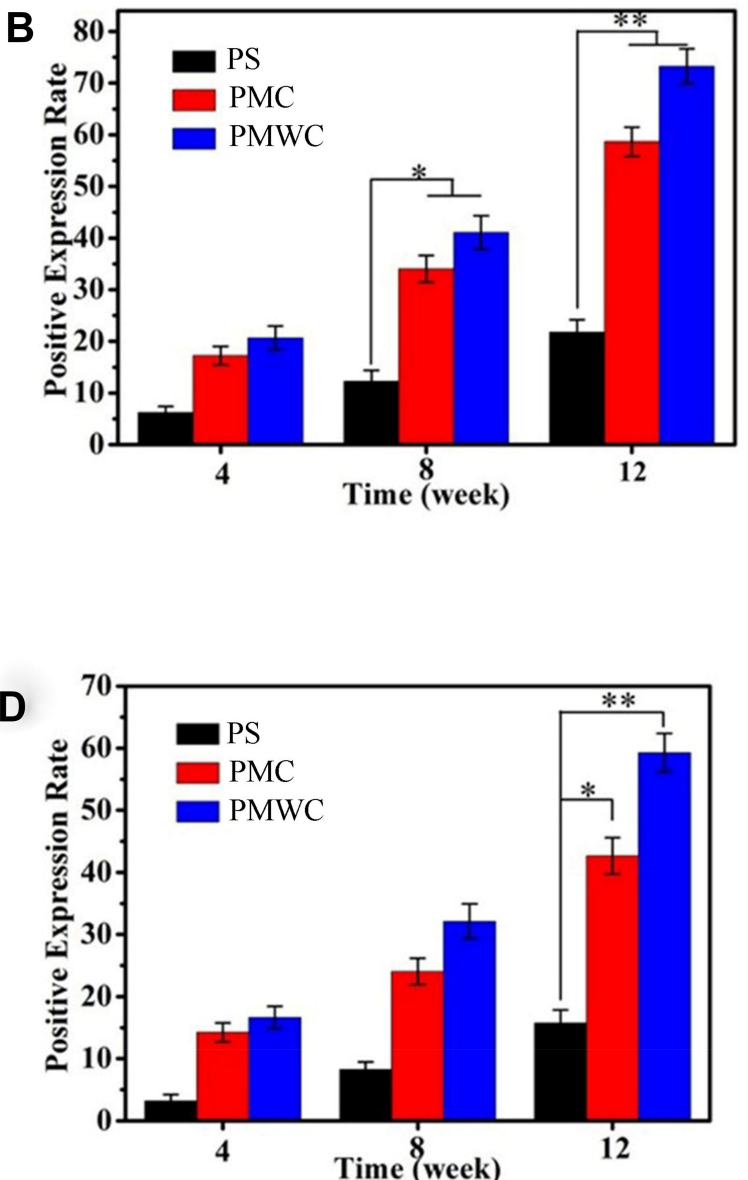

Figure 10 Immunohistological staining of positive expression of BMP-2 (A) and VEGF (C) after PS, PMC, and PMWC implanted in vivo for 4, 8 and I2 weeks. Brown staining indicates positive expression of BMP-2 and VEGF. Quantitative analysis of the positive expression of BMP-2 (B) and VEGF (D) by histological sections after PS, PMC, and PMWC implanted in vivo for 4,8 , and 12 weeks. $* p<0.05$ and $* * p<0.01$ relative to PS.

Abbreviations: BMP-2, bone morphogenetic protein-2; VEGF, vascular endothelial growth factor; PS, polybutylene succinate; PMC, polybutylene succinate-magnesium phosphate composite scaffolds; PMWC, polybutylene succinate-magnesium phosphate-wheat protein composite scaffolds.

the positive expressions of BMP-2 gradually increased with time. At 12 weeks, the positive expression of BMP2 on PMWC was much higher than on PMC, indicating that the osteogenic properties of PMWC were better than PMC. Nevertheless, the PS did not show good osteogenic properties from 4 to 12 weeks. In addition, the VEGF staining area (brown) increased with implantation time, indicating that the positive expressions of VEGF increased with time. At 12 weeks, the positive expression of VEGF for PMWC was higher than PMC, indicating that the vascularization of PMWC was better than PMC, while the PS showed the poorest vascularization from 4 to 12 weeks.
Figure 10B shows the quantitative analysis of positive expression of BMP-2 for PS, PMC, and PMWC scaffolds, which increased with implantation time. In a good agreement with Figure 10A, the positive expressions for PMWC were $20.66 \%, 41.12 \%$, and $73.28 \%$, at 4,8 , and 12 weeks, respectively. These values decreased to $17.24 \%, 34.06 \%$, and 58.67\% for PMC and 6.23\%, 12.29\%, and 21.77\% for PS, respectively. Figure 10D shows the quantitative analysis of positive expression of VEGF for PS, PMC, and PMWC scaffolds, which increased with implantation time. The positive expressions of VEGF for PMWC were $16.62 \%, 32.15 \%$, and $59.28 \%$, and slightly decreased to $14.27 \%, 24.03 \%$, and $42.69 \%$ for PMC, whereas they 
dramatically dropped to $3.27 \%, 8.19 \%$, and $15.71 \%$ for PS at 4,8 , and 12 weeks, respectively.

\section{Discussion}

PS possesses good biocompatibility, degradability, flexibility and processability. However, PS does not meet the requirement of bone regeneration due to its disadvantages, such as biological inertness and slow degradation rate, etc. ${ }^{8}$ Natural polymers are the most important raw materials for the development of biomedical materials. As one of the natural polymers, WP with excellent properties, such as good biocompatibility and biodegradability, has been applied in many fields including coating, encapsulation, drug release, and other biomedical fields. ${ }^{23-25}$ In this study, PMWC (containing $50 \mathrm{wt} \% \mathrm{PS}, 40 \mathrm{wt} \% \mathrm{MP}$ and $10 \mathrm{wt} \% \mathrm{WP}$ ) scaffold was fabricated using a method of solution casting and particulate leaching. The as-fabricated PMWC scaffold exhibited the well interconnected macroporous structure with the pore size ranging from $400 \mu \mathrm{m}$ to $600 \mu \mathrm{m}$, which were consistent with the size distribution of $\mathrm{NaCl}$ particles used as porogens. More interestingly, the PMWC not only possessed macropores, but also had micropores ranging from $10 \mu \mathrm{m}$ to $20 \mu \mathrm{m}$ on the walls of the macropores. The PMC and PMWC scaffolds showed slightly coarse surface because of the introduction of MP or MP and WP into PS while the PS exhibited smooth surface.

The compressive strengths of PS, PMC and PMWC scaffolds were 1.9 MPa, 2.8 MPa and 3.0 MPa, respectively. The results demonstrated that the addition of MP into PS improved compressive strength of the composite scaffolds, and the addition of $10 \mathrm{wt} \% \mathrm{WP}$ into PS had no obvious effects on the compressive strength of PMWC. The porosity of PS, PMC and PMWC scaffolds were $71.3 \%, 73.2 \%$ and $72.1 \%$, respectively. The results suggested that the incorporation of MP into PS did not have obvious effects on the porosity of the scaffolds as compared with PS. Moreover, PS had no obvious effects on the porosity of PMWC compared with PMC.

The ability to induce the apatite formation is an indicator of generating interfacial bonding with bone tissue when implanted in vivo. Apatite formation on the biomaterial surface when interacting with relevant biological fluids, such as SBF here, can verify in vitro bioactivity and predict the in vivo bone regeneration ability. The apatite formed efficiently on PMWC and PMC surfaces after immersion in SBF, whereas no apatite formation on PS, indicating that the bio-inert PS had been converted into bioactive scaffolds by incorporating MP and WP into PS. In addition, much more apatite formed on PMWC than PMC, suggesting that the WP exerted a positive influence on promoting apatite formation on PMWC. The presence of WP might have some effect on the microstructure, wettability or degradability of PMWC scaffolds, thus promoting the apatite mineralization. The apatite mineralization on PMWC and PMC surfaces could be interpreted as: once the degradation of MP was triggered in SBF, Mg and $\mathrm{P}$ ions released into the solution, meanwhile, the $\mathrm{Ca}$ and $\mathrm{P}$ ions in the solution precipitated on the scaffolds to form apatite, in which $\mathrm{P}$ ion release was considered as the leading process, which was consistent with the increase of $\mathrm{Mg}$ and $\mathrm{P}$ ion concentration, and the decrease of $\mathrm{Ca}$ ion concentration. The change of ion concentration in solution for PMWC was more significant than that of PMC because of the fast degradation of WP in the composites.

In the design and manufacture of scaffolds for bone tissue regeneration, appropriate degradability is desired. In this study, only a slight weight loss was observed for PS during the entire in vitro degradation period due to a random and bulk hydrolysis of the ester bonds in the PS chain. However, the weight loss of PMC and PMWC were more significant than PS, and gradually increased with time due to the degradation of MP in the composites. Furthermore, the weight loss of PMWC was higher than PMC because PMWC contained WP with a fast degradation rate. Meanwhile, the micropores in PMC and especially PMWC instead of smooth surface in PS, which might enlarge the contact area of scaffolds with PBS, improving degradation rate of PMWC in particular, which was in good agreement with previous studies. ${ }^{28,29}$

The release of acidic degradation by-products from some biomaterials would lead to inflammatory responses in vivo and many approaches have been tried to control the $\mathrm{pH}$ decrease during the degradation of biomaterials. In this study, the $\mathrm{pH}$ value for PS decreased from 7.40 to 7.32 , indicating the presence of an acidic product during degradation. However, the $\mathrm{pH}$ for PMC showed slight increase from the initial 7.40 to 7.59 during the degradation, this might be attributed to the dissolution of the MP, which released alkaline ions $\left(\mathrm{Mg}^{2+}\right){ }^{30}$ Furthermore, the $\mathrm{pH}$ for PMWC showed more moderate increase from the initial 7.40 to 7.51 during the degradation, indicating that some acidic products, such as amino acids, might be produced from WP degradation. Previous study has shown that weak alkaline condition provided a better microenvironment for 
cell proliferation and subsequently differentiation. ${ }^{31}$ Therefore, PMWC might supply a good microenvironment for cell proliferation and cell ingrowth both in vitro and in vivo.

The in vitro cell culture demonstrated that the cells on both PMWC and PMC presented better spreading with more pseudopods anchoring on the scaffold surface than on PS. This could be understood in two aspects: firstly, the presence of micropores on the walls of macropores of PMWC and PMC scaffolds, rather than PS, might be conducive to pseudopod anchorage, as suggested in earlier reports. $^{32,33}$ Secondly, MP and WP in the composites might have obvious effects on the cell growth, evidenced by the fact that the cell morphology on PMWC were better than PMC because of the incorporation of WP, and much better than PS due to the incorporation of both MP and WP. The subsequent cell proliferation and ALP results showed a similar tendency. Previous studies have shown that the $\mathrm{Mg}$ dissolution products from bioactive glasses/ ceramics stimulated proliferation and differentiation of osteoblasts. $^{34}$ Apparently, herein, the addition of WP improved the degradation rate of PMWC compared with PMC because of the fast degradation of WP. Furthermore, the fast degradation of PMWC promoted the degradation of MP in the composites, which further accelerated the $\mathrm{Mg}$ ion release from PMWC, and thus promoted cell proliferation and differentiation.

Implantation of PMWC scaffolds into femur defects of rabbits for different time periods was performed for a further investigation on in vivo osteogenesis and biocompatibility. The SRmCT results demonstrated that the bone defects were gradually repaired by $\mathrm{PMWC}$, significantly faster than PMC and PS, indicating that the PMWC promoted the restoration of bone defects. The histomorphometry analysis showed that the new bone tissues in both PMWC and PMC increased with time, indicating good osteogenesis. In addition, at both 4 and 12 weeks, more new bone tissues were found in PMC than in PS, indicating that the addition of MP into PS promoted the new bone formation in PMC. Furthermore, more new bone tissues were found in PMWC than in PMC, indicating that the addition of WP into PMC further improved the new bone regeneration in PMWC. Our results demonstrated that PMWC containing MP and WP stimulated bone tissue growth more efficiently in terms of the healing rate and quality of bone regeneration.

BMP-2 has been demonstrated to potently induce osteoblast differentiation in a variety of cell types. ${ }^{35}$ In addition, the BMP-2, like other bone morphogenetic proteins, plays an important role in the development of new bone, and the positive expression of BMP-2 is known to be of major importance in bone generation and reconstruction. ${ }^{36}$ Moreover, the vascularization of bone graft and bone substitute is the guarantee of successful transplantation. The procedure of vascularization involves the expression of VEGF, which has been identified as the key regulator factor for new bone regeneration. ${ }^{37}$ In this study, to evaluate the osteogenesis and vascularization of the scaffolds, the immunohistochemical staining and quantitative analysis of positive expression of BMP-2 and VEGF for PS, PMC, and PMWC scaffolds were carried out after being implanted in vivo for 4,8 , and 12 weeks.

The positive expression of BMP-2 for PMWC increased with implanted time, indicating that the osteogenic property of PMWC in vivo increased with time. In addition, the positive expression of BMP-2 for PMWC were higher than PMC, and PMC were higher than PS, indicating that the addition of MP into PS improved osteogenic property of PMC, and addition of WP into PMC further improved the osteogenic property of PMWC. Moreover, the positive expression of VEGF for PMWC increased with implanted time, indicating that the vascularization of PMWC increased with time. Furthermore, the positive expression of VEGF for PMWC were higher than PMC, and PMC were higher than PS, indicating that the addition of MP into PS promoted vascularization in PMC, and addition of WP further improved the vascularization of PMWC. The immunohistochemical analysis further confirmed that the PMWC containing MP and WP could promote osteogenesis and vascularization. Briefly speaking, this study demonstrated that the interconnected micromacroporous scaffold of PS/MP/WP ternary composite with improved bioactivity and degradability significantly promoted the osteogenesis and vascularization in vivo, which might have great potential to be applied for bone tissue generation and to repair bone defects.

\section{Conclusion}

The interconnected micro-macroporous scaffold of PS/ MP/WP ternary composite was fabricated in this study. The results demonstrated that incorporation of MP into PS obviously improved the degradability and bioactivity of PMC scaffold. Moreover, addition of WP into PMC further enhanced the degradability and bioactivity of PMWC scaffold. The in vitro cell experiments demonstrated that the PMWC scaffold containing MPC and WP 
significantly promoted the cells proliferation and differentiation as compared with PMC and PS. The in vivo study showed that the PMWC containing MP and WP remarkably stimulated the new bone formation and ingrowth compared with PMC and PS. Furthermore, the results of immunohistochemistry further offered the evidence that PMWC promoted osteogenesis and vascularization. In short, the PMWC exhibited good biocompatibility, bioactivity, degradability, osteogenesis and vascularization, which would be an excellent ternary composite scaffold for bone tissue regeneration.

\section{Acknowledgments}

This work was sponsored by Major Program of Development Fund for Shanghai Zhangiiang National Innovation Demonstration Zone (ZJ2018-ZD-004) and Peak Disciplines (Type IV) of Institutions of Higher Learning in Shanghai.

\section{Disclosure}

The authors report no conflicts of interest in this work.

\section{References}

1. Laino L, Iezzi G, Piattelli A, Lo Muzio L, Cicciu M. Vertical ridge augmentation of the atrophic posterior mandible with sandwich technique: bone block from the chin area versus corticocancellous bone block allograft-clinical and histological prospective randomized controlled study. Biomed Res Int. 2014;2014:982104.

2. Cicciu M, Scott A, Cicciu D, Tandon R, Maiorana C. Recombinant human bone morphogenetic protein-2 promote and stabilize hard and soft tissue healing for large mandibular new bone reconstruction defects. J Craniofac Surg. 2014;25(3):860-862. doi:10.1097/ SCS. 0000000000000830

3. Herford AS, Tandon R, Stevens TW, Stoffella E, Cicciu M. Immediate distraction osteogenesis: the sandwich technique in combination with rhBMP-2 for anterior maxillary and mandibular defects. J Craniofac Surg. 2013;24:1383-1387. doi:10.1097/SCS.0b $013 \mathrm{e} 318292 \mathrm{c} 2 \mathrm{ce}$

4. Herford AS, Cicciu M, Eftimie LF, et al. rhBMP-2 applied as support of distraction osteogenesis: a split-mouth histological study over nonhuman primates mandible. Int $J$ Clin Exp Med. 2016;9:17 187-17194.

5. Petrauskaite O, Gomes PDS, Fernandes MH, et al. Biomimetic mineralization on a microporous cellulose-based matrix for bone regeneration. Biomed Res Int. 2013;452750.

6. Yao QQ, Cosme JGL, Xu T, et al. Three dimensional electrospun PCL/ PLA blend nanofibrous scaffolds with significantly improved stem cells osteogenic differentiation and cranial bone formation. Biomaterials. 2017;115:115-127. doi:10.1016/j.biomaterials.2016.11.018

7. Kim HS, Yang HS, Kim HJ. Biodegradability and mechanical properties of agro-flour-filled polybutylene succinate biocomposites. $J$ Appl Polym Sci. 2005;97:1513-1521. doi:10.1002/app.21905

8. Costa-Pinto AR, Correlo VM, Sol PC, et al. Chitosan-poly(butylene succinate) scaffolds and human bone marrow stromal cells induce bone repair in a mouse calvaria model. J Tissue Eng Regen Med. 2012;6(1):21-28. doi:10.1002/term.391
9. Oliveira JT, Correlo VM, Sol PC, et al. Assessment of the suitability of chitosan/polybutylene succinate scaffolds seeded with mouse mesenchymal progenitor cells for a cartilage tissue engineering approach. Tissue Eng Part A. 2008;14(10):1651-1661. doi:10.1089/ ten.tea.2007.0307

10. Saris NEL, Mervaala E, Karppanen H, Khawaja JA, Lewenstam A. Magnesium-an update on physiological, clinical and analytical aspects. Clin Chim Acta. 2000;294:21-26.

11. Maradze D, Capel A, Martin N, Lewis MP, Zheng YF, Liu Y. In vitro investigation of cellular effects of magnesium and magnesium-calcium alloy corrosion products on skeletal muscle regeneration. J Mater Sci Technol. 2019;35(11):2503-2512. doi:10.10 16/j.jmst.2019.01.020

12. Yuan ZY, Wei PF, Huang YQ, et al. Injectable PLGA microspheres with tunable magnesium ion release for promoting bone regeneration. Acta Biomater. 2019;85:294-309. doi:10.1016/j.actbio.2018.12.017

13. Rude RK, Gruber HE. Magnesium deficiency and osteoporosis: animal and human observations. J Nutr Biochem. 2004;15(12):710-716. doi:10.1016/j.jnutbio.2004.08.001

14. Fiocco L, Li S, Stevens MM, Bernardo E, Jones JR. Biocompatibility and bioactivity of porous polymer-derived Ca-Mg silicate ceramics. Acta Biomater. 2017;50:56-67. doi:10.1016/j.actbio.2016.12.043

15. Singh S, Vashisth P, Shrivastav A, Bhatnagar N. Synthesis and characterization of a novel open cellular Mg-based scaffold for tissue engineering application. $J$ Mech Behav Biomed. 2019;94:54-62. doi:10.1016/j.jmbbm.2019.02.010

16. Bose J, Babourina O, Rengel Z. Role of magnesium in alleviation of aluminium toxicity in plants. $J$ Exp Bot. 2011;62(7):2251-2264. doi:10.1093/jxb/erq456

17. Khalajabadi SZ, Ahmad N, Yahya A, et al. The role of titania on the microstructure, biocorrosion and mechanical properties of $\mathrm{Mg}$ / HA-based nanocomposites for potential application in bone repair. Ceram Int. 2016;42(16):18223-18237. doi:10.1016/j.ceramint.2016. 08.146

18. Flahiff CM, Blackwell AS, Hollis JM, Feldman DS. Analysis of a biodegradable composite for bone healing. J Biomed Mater Res. 1996;32(3):419-424. doi:10.1002/(SICI)1097-4636(199611) 32:3<419::AID-JBM15>3.0.CO;2-B

19. Zhu WM, Huang JH, Lu W, et al. Performance test of nano-HA/ PLLA composites for interface fixation. Artif Cell Nanomed B. 2014;42(5):331-335. doi:10.3109/21691401.2013.827120

20. Bouler JM, Pilet P, Gauthier O, Verron E. Biphasic calcium phosphate ceramics for bone reconstruction: a review of biological response. Acta Biomater. 2017;53:1-12. doi:10.1016/j.actbio.2017.01.076

21. Eliaz N, Metoki N. Calcium phosphate bioceramics: a review of their history, structure, properties, coating technologies and biomedical applications. Materials. 2017;10(4):334. doi:10.3390/ma10040334

22. Pina S, Oliveira JM, Reis RL. Natural-based nanocomposites for bone tissue engineering and regenerative medicine: a review. $A d v$ Mater. 2015;27(7):1143-1169. doi:10.1002/adma.201403354

23. Reddy N, Yang YQ. Potential of plant proteins for medical applications. Trends Biotechnol. 2011;29(10):490-498. doi:10.1016/ j.tibtech.2011.05.003

24. Yan X, Zhou PY, Wang F. Degradability, biocompatibility, and osteogenesis of biocomposite scaffolds containing nano magnesium phosphate and wheat protein both in vitro and in vivo for bone regeneration. Int J Nanomed. 2016;11:3435-3449. doi:10.2147/IJN. S105645

25. Feng SP, Li JY, Jiang XS, et al. Influences of mesoporous magnesium silicate on the hydrophilicity, degradability, mineralization and primary cell response to a wheat protein based biocomposite. $J$ Mater Chem B. 2016;4(39):6428-6436. doi:10.1039/C6TB01449F

26. Reddy N, Jiang QR, Yang YQ. Novel wheat protein films as substrates for tissue engineering. J Biomat Sci Polym E. 2011;22 (15):2063-2077. doi:10.1163/092050610X532638 
27. Xu HL, Cai SB, Sellers A, Yang YQ. Electrospun ultrafine fibrous wheat glutenin scaffolds with three-dimensionally random organization and water stability for soft tissue engineering. J Biotechnol. 2014;184:179-186. doi:10.1016/j.jbiotec.2014.05.011

28. Liu Y, Luo D, Wang T. Hierarchical structures of bone and bioinspired bone tissue engineering. Small. 2016;12(34):4611-4632. doi:10.1002/smll.201600626

29. Wu XH, Wu ZY, Su JC, et al. Nano-hydroxyapatite promotes self-assembly of honeycomb pores in poly(l-lactide) films through breath-figure method and MC3T3-E1 cell functions. RSC $A d v$. 2015;5:6607-6616. doi:10.1039/C4RA13843K

30. Wei J, Jia JF, Wu F, et al. Hierarchically microporous/macroporous scaffold of magnesium-calcium phosphate for bone tissue regeneration. Biomaterials. 2015;31:1260-1269. doi:10.1016/j.biomaterials. 2009.11.005

31. Chen ZT, Mao XL, Tan LL, et al. Osteoimmunomodulatory properties of magnesium scaffolds coated with beta-tricalcium phosphate. Biomaterials. 2014;35:8553-8565. doi:10.1016/j.biomaterials.2014. 06.038

32. Wu XH, Wang SF. Regulating MC3T3-E1 cells on deformable poly ( $\varepsilon$-caprolactone) honeycomb films prepared using a surfactant-free breath figure method in a water-miscible solvent. ACS Appl Mater Inter. 2012;4:4966-4975. doi:10.1021/am301334s

33. Wu XH, Wang SF. Integration of photo-crosslinking and breath figures to fabricate biodegradable polymer substrates with tunable pores that regulate cellular behavior. Polymer. 2014;55:1756-1762. doi:10.1016/j.polymer.2014.02.029

34. Toba Y, Kajita Y, Masuyama R, Takada Y, Suzuki K, Aoe S. Dietary magnesium supplementation affects bone metabolism and dynamic strength of bone in ovariectomized rats. J Nutr. 2000;130:216-220. doi:10.1093/jn/130.2.216

35. Chen S, Shi XT, Osaka A, Gao H, Hanagata N. Facile synthesis, microstructure and BMP-2 delivery of novel silica hollow flowers for enhanced osteoblast differentiation. Chem Eng J. 2014;246:1-9. doi:10.1016/j.cej.2014.02.053

36. Lee GH, Makkar P, Paul K, Lee B. Incorporation of BMP-2 loaded collagen conjugated BCP granules in calcium phosphate cement based injectable bone substitutes for improved bone regeneration. Mater Sci Eng C. 2017;77:713-724. doi:10.1016/j.msec.2017.03.296

37. Poldervaart MT, Gremmels H, van Deventer K, et al. Prolonged presence of VEGF promotes vascularization in 3D bioprinted scaffolds with defined architecture. J Control Release. 2014;184:58-66. doi:10.1016/j.jconrel.2014.04.007
International Journal of Nanomedicine

\section{Publish your work in this journal}

The International Journal of Nanomedicine is an international, peerreviewed journal focusing on the application of nanotechnology in diagnostics, therapeutics, and drug delivery systems throughout the biomedical field. This journal is indexed on PubMed Central, MedLine, CAS, SciSearch ${ }^{\circledR}$, Current Contents ${ }^{\circledR} /$ Clinical Medicine,

\section{Dovepress}

Journal Citation Reports/Science Edition, EMBase, Scopus and the Elsevier Bibliographic databases. The manuscript management system is completely online and includes a very quick and fair peer-review system, which is all easy to use. Visit http://www.dovepress.com/ testimonials.php to read real quotes from published authors. 